\title{
CORRECTION TO: SMOOTH AND STRONG PCPS
}

\author{
ORR PARADISE
}

\section{Correction to: comput. complex. (2021) 30:1} https://doi.org/10.1007/s00037-020-00199-3

Authors would like to correct the error in their publication.

On page 13, a reference has not rendered properly: (e.g., Gal \& Mills 2012; Yekhanin 2012; ?)

The "?" should refer to Goldreich et al. 2006.

The original article has been corrected.

\section{Publisher's Note}

Springer Nature remains neutral with regard to jurisdictional claims in published maps and institutional affiliations.

ORR PARAdise

Electrical Engineering and

Computer Sciences Department

University of California

Berkeley

396 Soda Hall \#1776

Berkeley, CA 94720-1776, USA

orrp@eecs.berkeley.edu

http://people.eecs.berkeley.edu/ orrp/ 